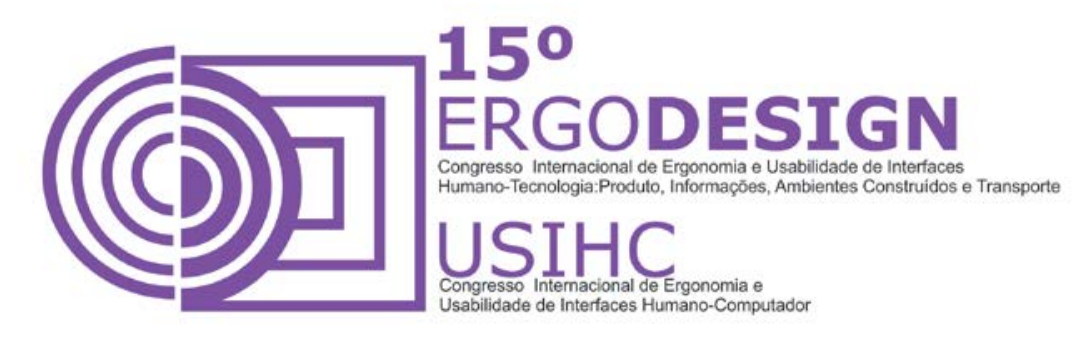

\title{
ASPÉCTOS INCLUSIVOS DO DESIGN DE MODA PARA CRIANÇAS COM CEGUEIRA
}

\section{ASPECTS INCLUSIVE FASHION DESIGN FOR CHILDREN WITH BLINDNESS}

\author{
BONONI, Juliana (1); \\ CARVALHO, J. A. (2); \\ DOMICIANO, Cássia Letícia Carrara (3) \\ PINHEIRO, Olympio José (4) \\ PASCHOARELLI, Luis Carlos (5) \\ MEDOLA, Fausto Orsi (6)
}

(1) Programa de Pós-graduação em Design, Faculdade de Arquitetura, Artes e Comunicação, UNESP-Bauru, Mestranda

julianabs9@gmail.com

(2) Programa de Pós-graduação em Design, Faculdade de Arquitetura, Artes e Comunicação, UNESP-Bauru, Graduado em Desenho Industrial

juliano a.c@hotmail.com

(3) Programa de Pós-graduação em Design, Faculdade de Arquitetura, Artes e Comunicação, UNESP-Bauru, Professora Doutora

\section{carrara@faac.unesp.br}

(4) Programa de Pós-graduação em Design, Faculdade de Arquitetura, Artes e Comunicação, UNESP-Bauru, Professor Doutor

\section{holihn@uol.com.br}

(5) Programa de Pós-graduação em Design, Faculdade de Arquitetura, Artes e Comunicação, UNESP-Bauru, Professor Doutor

\section{paschoarelli@faac.com.br}

(6) Programa de Pós-graduação em Design, Faculdade de Arquitetura, Artes e Comunicação, UNESP-Bauru, Professor Doutor 


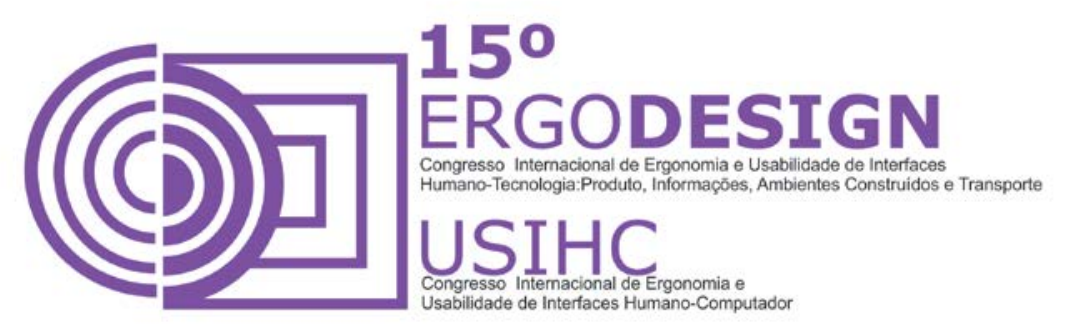

\section{RESUMO}

Este estudo tem como objetivo discutir as questões principais que relacionam moda e deficiência visual infantil. A discussão é feita a partir de uma revisão bibliográfica, e busca proporcionar um olhar sobre as novas possibilidades trazidas pelo design inclusivo na moda. Demonstra-se de que forma a indústria da moda tem trabalhado a percepção tátil das crianças com deficiência visual por meio do vestuário, destacando a necessidade de uma abordagem multidisciplinar ao design. Ainda que alguma evolução possa ser notada, existem ainda grandes desafios para que se possa atender às necessidades e expectativas de crianças com baixa visão.

Palavras-chave: vestuário infantil; percepção tátil; deficiência visual; inclusão social.

\section{ABSTRACT}

This study aims to discuss the main issues relating fashion and children's visual impairment. The discussion is made from a literature review, and seeks to provide a look at the new opportunities brought by the inclusive design. It is shown how the fashion industry has worked the tactile perception of children with visual disabilities through clothing, highlighting the need for a multidisciplinary approach to design. Although some progress can be noted, there are still major challenges so that we can meet the needs and expectations of children with low vision.

Keywords: Children's clothing; tactile perception; visual impairment; social inclusion.

\section{INTRODUÇÃO}

A inclusão social nada mais é que o compartilhamento de recursos e ambientes acessíveis por todos, é o pensamento nas pessoas com deficiência, com problemas de mobilidade reduzida, orientação direcional, entre outros (GUIMARÃES, 2010). Para o desenvolvimento de bons produtos voltados à área do design inclusivo apenas pesquisas teóricas e embasamentos técnicos não resultarão em um produto de grande sucesso. (FERRÉS 2005 apud GUIMARÃES; GUIMARÃES, 2010).

Oliveira (1998) afirma que "As pesquisas mais recentes atestam que os olhos são responsáveis por no mínimo $80 \%$ das impressões recebidas através da sensibilidade. Habitamos um mundo que se manifesta de forma predominantemente visual." Esta perspectiva tem implicações diretas no design, evidenciada na seguinte citação de MUNARI (1998):

Muitos designers projetam ainda hoje apenas para o sentido da visão. Preocupam-se unicamente em produzir algo belo de se ver e não Ihes interessa que o objeto resulte depois desagradável ao tato, se não tem relações formais com a anatomia humana (...) ou então não se importam de usar materiais que impedem o corpo de transpirar como acontece com algumas cadeiras e poltronas (...) que apesar de muito bonitas são desconfortáveis (MUNARI, 1998, p. 373). 


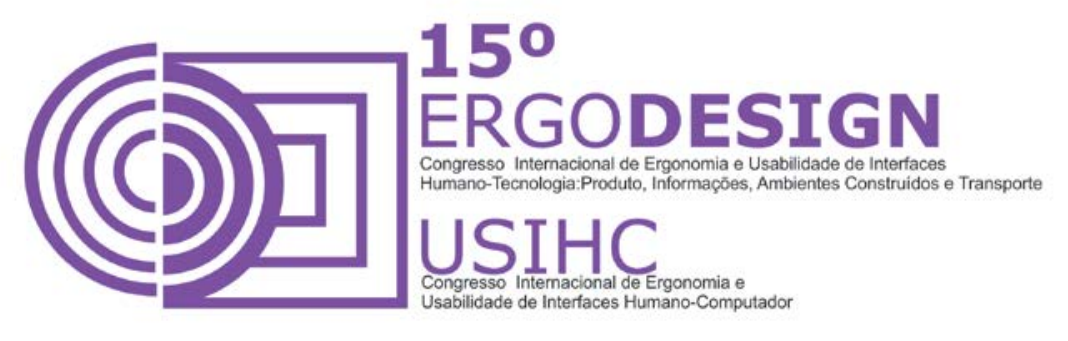

Após tantos anos, Maximiliano e Tomasulo (2013), afirmam que em nossa sociedade, muitas pessoas são extremamente visuais, e atribuem esse fato aos indícios da importância dada em relação à aparência e a características visuais que se desperta nas pessoas, o que contribuiu para o aumento no mercado de beleza nos últimos anos. No universo da moda não seria diferente, pois, é um mercado que cresce num ritmo significativo, com novas tendências, temáticas, cores, tecidos e modelagens que despertam o interesse e desejo em consumidores do mundo inteiro. A moda possui forte apelo visual para aqueles que a desenvolvem e mais ainda para os que a consomem, porém, uma peça de roupa não é somente algo visual, ela pode trazer experiências sensoriais que estimulam outros sentidos, adquiridos por meio do toque que determinados tecidos proporcionam, como também o olfato que vem sendo empregado em diversos produtos e marcas. Além disso, na hora de comprar uma roupa nova, o caimento é item indispensável, pois, procura-se algo que se molde adequadamente ao corpo do usuário.

Este artigo tem como objetivo discutir as relações entre design de moda e deficiência visual infantil, e observar se há indústrias de confecções que estão trabalhando a percepção tátil dessas crianças por meio do vestuário. Parte-se de um levantamento bibliográfico sobre a deficiência visual com foco na criança com cegueira e a importância de desenvolver o estímulo tátil infantil, com a intenção de gerar discussões a respeito do assunto e proporcionar um olhar a respeito das novas transformações sociais, não apenas no meio acadêmico, mas também na vida social dos envolvidos.

\section{REVISÃO TEÓRICA}

\subsection{DEFICIÊNCIA VISUAL}

Para Lima et al. (2013), o termo deficiência visual refere-se à diminuição da resposta visual, que pode ser leve, moderada, severa ou profunda. Acomete um grupo de pessoas com visão subnormal ou pessoas com baixa visão; ou a ausência total da resposta visual (cegueira). O indivíduo que perdeu a visão precisa de acompanhamento familiar e, principalmente, psicológico, pois a cegueira causa um grande impacto na vida da pessoa, e suas consequências são potencialmente danosas e até irreversíveis.

Segundo a Cartilha on-line do IBGE senso 2010,

"O conceito de deficiência vem se modificando para acompanhar as inovações na área da saúde e a forma com que a sociedade se relaciona com a parcela da população que apresenta algum tipo de deficiência. Dessa forma, a abordagem da deficiência evoluiu do modelo médico - que considerava somente a patologia física e o sintoma associado que dava origem a uma incapacidade - para um sistema como a Classificação Internacional de Funcionalidade, Incapacidade e Saúde - CIF, divulgada pela Organização Mundial da Saúde - OMS (World Health Organization - WHO) em 2001, que entende a incapacidade como um resultado tanto da limitação das funções e 


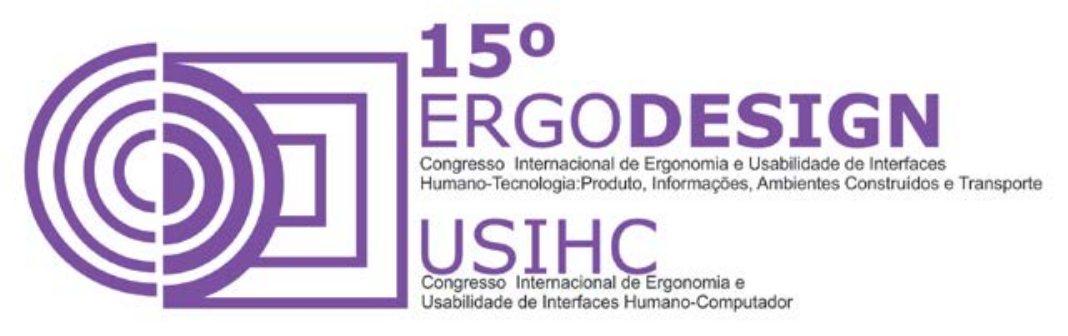

estruturas do corpo quanto da influência de fatores sociais e ambientais sobre essa limitação." (IBGE censo demográfico 2010 pág71)

Atualmente, é possível observar mais pessoas portadoras de deficiências físicas nas ruas, isso se deve às várias propostas de mudanças e adaptações nos espaços urbanos e nos meios de transporte para que os deficientes possam se locomover com maior facilidade, e os resultados vêm se apresentando gradativamente, com mais visibilidade. Tais adaptações têm possibilitado um maior deslocamento dessas pessoas que, como resultado, ganham em independência e autoestima ao perceberem as inúmeras possibilidades de explorar locais muitas vezes em seu imaginário inatingíveis.

Segundo Cunha et al (2011), os indivíduos com cegueira são aqueles em que a visão é nula ou diminuída a ponto de incapacitá-los para o exercício da maioria das tarefas diárias. Por sua vez, os indivíduos com baixa visão são aqueles que apresentam acuidade visual de 0,25 a 0,02 no melhor olho, após correção máxima. Existem ainda os indivíduos com a restrição do campo visual, visão em túnel, que, independentemente da acuidade visual que possuem, também são considerados cegos, já que qualquer visão nesta amplitude impede a apreensão do ambiente de forma ampla e irrestrita.

A cegueira não envolve a chamada "compensação", quando um sentido "compensa" a falta do outro, a "compensação" deve ser compreendida como um processo social e não orgânico, os sentidos remanescentes são mais desenvolvidos pelos cegos porque eles recorrem a esses sentidos com mais frequência do que as pessoas sem a deficiência visual. Isto é, o cego não ouve melhor do que o não cego, apenas tem a escuta treinada, porque utiliza mais esse sentido (ULBRICHT et al., 2011; SÁ et al., 2007; CAIADO, 2006).

O censo de 2010 apontou que para cada grupo de 100,0 crianças de 0 a 14 anos de idade $7,5 \%$ apresentam alguma deficiência, e entre elas 5,3\% é a visual (IBGE, 2010). Essa deficiência não é apontada como maior índice apenas nas crianças, nos adultos ela também se apresenta em maior porcentagem, mas para esse trabalho o foco será grupo infantil.

Ferreira e Morellato (2012) afirmaram que a deficiência "advém da interação entre corpos comprometidos e ambientes excludentes", muitas vezes é este ambiente excludente que exacerba a condição de "sentir-se deficiente" do cego através de um enfraquecimento moral que vem desta incapacidade de realizar certas tarefas.

Observa-se que a sociedade passou a enxergar as dificuldades impostas na vida dos deficientes e sinaliza com mudanças favoráveis, na tentativa de adaptar-se à realidade deles e criar oportunidades de melhor qualidade de vida no trabalho, laser e estudo. O vestuário, assim como os espaços urbanos e meios de transportes, deve contribuir para maior independência e praticidade.

Sassaki (1997) defende que a sociedade precisa se adaptar às necessidades da pessoa com deficiência. Entendemos que esse é o ponto de partida para que haja inclusão, para que a pessoa com deficiência possa desenvolver-se nos diferentes aspectos de sua vida. 


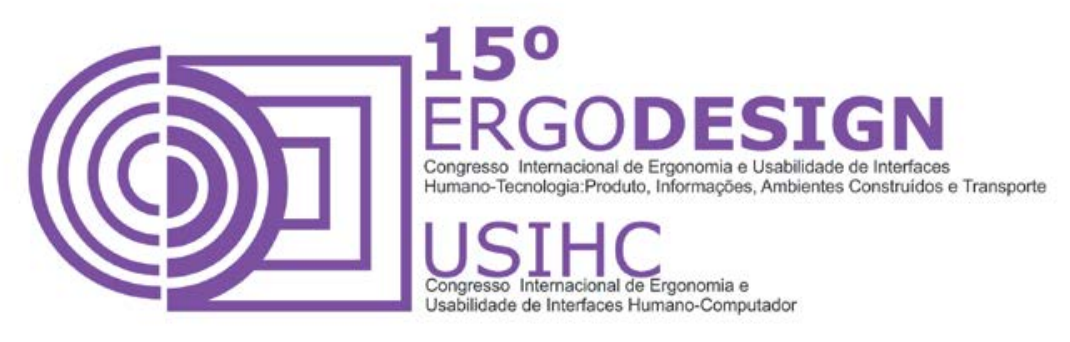

\subsection{CRIANÇA COM CEGUEIRA}

Para o design de moda, a criança com deficiência visual não apresenta alteração de sua estrutura física, portanto faz uso do mesmo vestuário das crianças com visão não afetada. No entanto, a percepção da criança com relação ao vestuário, assim como a interação durante 0 ato de vestir-se, merece atenção especial em seus aspectos estéticos, práticos e perceptivos.

Machado (2003), afirma que a criança cega muitas vezes chega à escola sem um "passado" de experiências como seus colegas que enxergam, não apresentam as rotinas da vida cotidiana de acordo com a sua idade, os seus conceitos básicos como esquema corporal, lateralidade, orientação espacial e temporal são quase inexistentes e sua mobilidade difícil, o que poderá levar à baixa autoestima e dificultará o seu ajustamento à situação escolar, isto é, a sua inclusão de fato.

Ulbricht et al (2011), afirmam que muitos pesquisadores (DIAS, 1995; AMILARIAN, 1997; SOLER, 1999; CAIADO, 2003; LEME, 2003; NUNES, 2004) indicam que os atrasos de desenvolvimento motor e cognitivo na aprendizagem do deficiente visual não ocorrem devido à deficiência, mas devido à falta de experiências diversificadas que permitam seu acesso à cultura, ao entorno e ao contexto em que se insere.

Quando se trata de crianças com necessidades especiais, as questões relacionadas à interação social se tornam ainda mais importantes, já que, as mesmas possuem algumas limitações, e são frequentemente consideradas incapazes de participar e contribuir nas atividades em grupo, muitas vezes são isoladas do contato com parceiros e têm suas interações restritas à relação com o adulto (SOUZA; BATISTA, 2008). Esse isolamento pode ocorrer nas relações com parentes e vizinhos, na escola, e nas relações de caráter terapêutico.

Para Oliveira et al. (2002), a ausência da modalidade visual exige experiências alternativas de desenvolvimento, a fim de cultivar a inteligência e promover capacidades sócio-adaptativas. O ponto central desses esforços é a exploração do pleno desenvolvimento tátil. Os autores afirmam ainda que a modalidade tátil se desenvolve por um processo de crescimento gradual e sequencial, levando as crianças cegas de um reconhecimento simplista a uma interpretação complexa do ambiente. Os pais e educadores têm um papel importantíssimo neste processo podem estimular o desenvolvimento dessas crianças desde a infância. Mais ainda, como responsáveis por crianças cegas, eles devem continuar a dar ênfase ao desenvolvimento tátil durante toda a vida destas crianças, já que essa é a base para os níveis mais altos do desenvolvimento cognitivo.

Os profissionais que atuam na educação, habilitação e reabilitação de escolares com baixa visão necessitam conhecer esta população, porque quanto maior o conhecimento, melhor será a elaboração de um programa de habilitação e/ou reabilitação visual, propiciando desenvolvimento, transmissão de conhecimentos de acordo com as necessidades de cada um, transformação em novos saberes, aprendizagem e preparo para a inclusão social (FERRONI; GASPARETTO, 2012). 


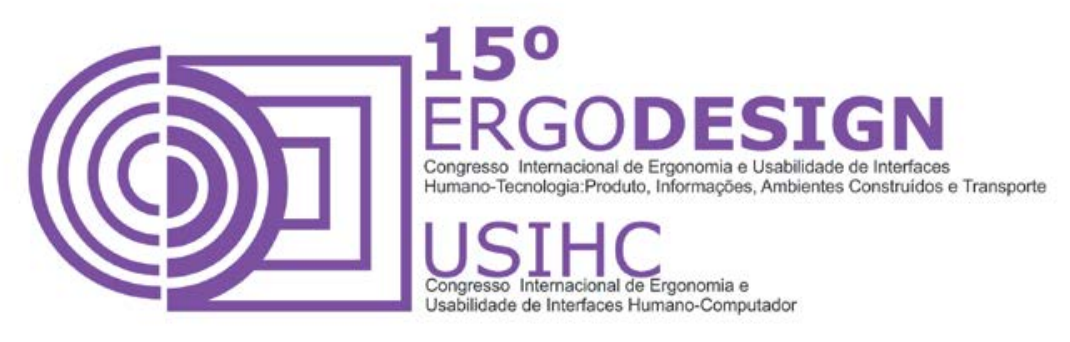

\subsection{PERCEPÇÃO TÁTIL INFANTIL}

A percepção tátil é muito útil para a criança cega, sendo que Gerber e Grifin (s/d) em sua pesquisa exploram o desenvolvimento da modalidade tátil, observando que esta vai além do mero sentido do tato; inclui também a percepção e a interpretação por meio da exploração sensorial, porém menos refinadas que as fornecidas pela visão. Os autores trazem o conceito da compreensão das sequências do desenvolvimento dentro da modalidade tátil, sendo elas:

a) Consciência de qualidade tátil: compreensão das características táteis dos objetos, no que envolve o contato com texturas, temperaturas, superfícies vibráteis, diferentes consistências, contornos, tamanhos e pesos.

b) Reconhecimento de forma: nesta fase a criança desenvolve a capacidade de distinguir formas e discernir entre figura e fundo.

c) Compreensão de representações gráficas: aprendizado de relevos, linhas retas e curvas, formas geométricas e contornos de objetos, dimensionalidade, percepção de proporção de objetos.

d) Utilização de simbologia: fase que a criança reconhece o sistema Braille, por exemplo, onde entra em contato com o mundo de uma forma mais profunda, aprendendo novos códigos de comunicação.

Lima Júnior (2006) descreve a percepção da pele em contato com o mundo:

"A pele é o contato do meu corpo com o mundo em que vivo. Através dela conecto-me com o outro e sinto sua presença. Ao tocá-lo, posso senti-lo em categorias táteis distintas. Viver é estar envolto pela pele, cobertura necessária e geradora de prazeres, mas também de dores, que acompanha cada um de nós durante todos os nossos dias. Para cada um, ela se modifica, elastifica, pregueia, dobra, colore- se, conforma-se de acordo com o corpo que envolve. Úmida, seca, molhada, fria ou quente, ela reage com o ambiente a fim de proporcionar bem estar." (LIMA JÚNIOR, 2006 p.2).

A modalidade tátil é de ampla confiabilidade. Vai além do mero sentido do tato; inclui também a percepção e a interpretação por meio da exploração sensorial. Esta modalidade fornece informações a respeito do ambiente, menos refinadas que as fornecidas pela visão. As informações obtidas por meio do tato têm de ser adquiridas sistematicamente, e reguladas de acordo com o desenvolvimento, para que os estímulos ambientais sejam significativos (OLIVEIRA et al., 2002).

Ferreira e Morellato (2012), em sua pesquisa de campo destacam o fascínio que as cores exercem entre os cegos, que:

"Quando se deparam com algum objeto, podem conhecê-lo mesmo sem ter visão, podem tocá-lo, cheirá-lo, apalpá-lo. Assim, sabem, por exemplo, o formato e a textura de uma determinada roupa. A única coisa que não podem tatear, que necessariamente precisam ser vistas, são as cores. Inúmeras vezes 


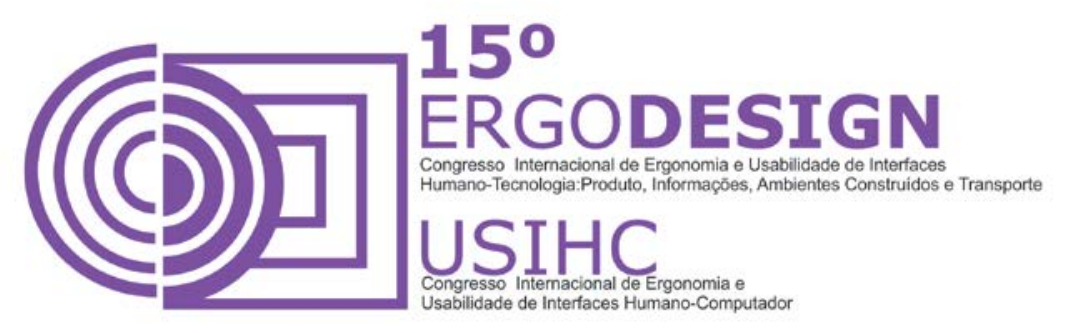

durante as conversas que tivemos com os habitantes do Lar dos Cegos fomos perguntados sobre cores. Nos perguntavam de que cor era determinado objeto, se ele possuía um padrão ou uma cor lisa, e muitas vezes nos pediam para explicar uma cor ou um padrão, uma tarefa nada fácil." (FERREIRA E MORELLATO, 2012 p.8).

A qualidade tátil implica em que as crianças aprendam a mover as mãos para explorar objetos, que devem ser apresentados gradativamente para que conheçam várias texturas, como: duro e mole, macio e áspero. Com o aperfeiçoamento gradual das técnicas de percepção, podem aprender tamanhos e pesos relativos a objetos. Com o tempo as comparações vão deixando de ser grosseiras para se tornarem refinadas.

\section{O DESIGN DE MODA INFANTIL}

$\mathrm{Na}$ Idade Média, não havia distinção entre adultos e crianças, nos séculos XV e XVI esse contexto apresentou mudanças e as crianças começaram a ser reconhecidas como seres diferentes dos adultos. No século XVII essa consciência aumentou, porém o tratamento dispensado às crianças ainda era secundário (CARDOSO 2004 apud PINHEIRO E SANCHES; PINHEIRO E SANCHES, 2006).

Até o século XVIII, as crianças ainda eram submetidas a roupas com a mesma aparência das de seus pais, forçando-as a permanecer comportadas nos espaços que lhe eram destinados. Foi por volta de 1762, que o filósofo Jean Jacques Rousseau começou a combater essa vestimenta que não dava liberdade às crianças, com o apoio de educadores, médicos e outros filósofos da época. Foram as primeiras reações para que as roupas se tornassem mais leves e com uma conotação infantil. Este movimento, lentamente, influenciou a adoção de tecidos leves e cores mais claras, eliminando as armações das saias. (ROCHA, 2002).

Segundo Gonçalves (2007), foi só na segunda metade do século XX que as roupas infantis sofreram maiores transformações: "os trajes complicados que obrigavam as crianças a brincarem comportadamente, especialmente as de maior poder aquisitivo, foram simplificados. As crianças passaram a ser mais livres para desenvolver suas atividades e adquiriram o direito de intervir na composição do seu guarda roupa e, as diferenças nas vestimentas, entre as classes sociais, diminuíram consideravelmente, ao menos na vida diária." Segundo o autor, somente a partir de 1960 que as roupas passaram a ser produzidas por segmentos - esporte, passeio e festa - atendendo à questões como: considerações de entendimento do usuário, clareza no manuseio, consistência, priorização da funcionalidade e das informações foram sendo inseridos, gradativamente. É na elaboração de um produto do vestuário, especialmente no processo de modelagem de uma peça e no tipo de tecido utilizado, que o usuário obtém a eficácia, que é a qualidade com que o utilizador atinge os objetivos; a eficiência, que é quando se despende recursos, com modelagem, maquinário, cores, formas, design, aviamentos, para que o produto atenda os objetivos do consumidor; e a satisfação, que é o nível de conforto e o grau de aceitação por parte do usuário. Além disso, outro aspecto que se deve levar em 


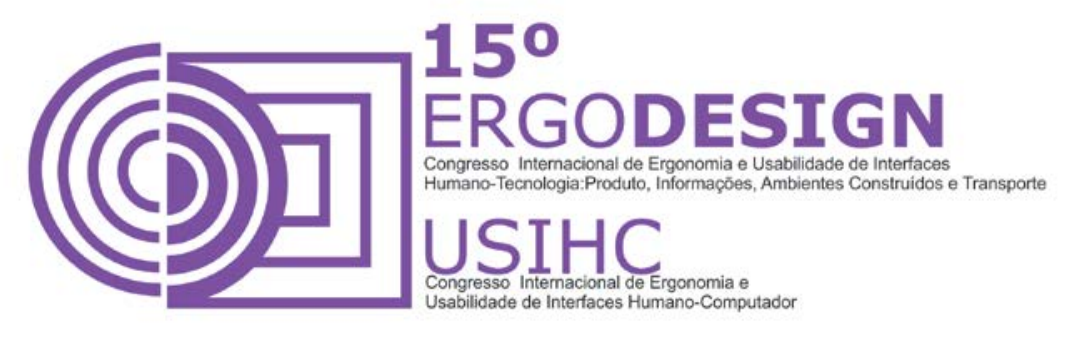

consideração é o estético, responsável, em parte, pela satisfação emocional do cliente. O produto do vestuário, além de ser funcional, deve ser esteticamente confortável.

Brito (2010), destaca que as marcas infantis tem ganhado o mercado com peças coloridas, lojas aconchegantes e adaptadas para atender este público, os tecidos desse vestuário são diversos, mas o mais procurado é o algodão, pela maciez e delicadeza de contato com a pele sensível da criança. A funcionalidade das roupas faz grande importância na hora da escolha. Aplicações, estampas e listras são bem aceitas para o público infantil, é um mercado consumidor crescente e passível de criações elaboradas, como é visto em grandes desfiles de moda como Rio Fashion Week, que apresenta algumas marcas infantis.

Barbosa e Quedes (2007), afirmam que o design da roupa infantil requer conforto tanto na modelagem como nos tecidos utilizados. Criança precisa de liberdade de movimentos para andar, correr, pular, brincar e roupas desconfortáveis dificultam esses movimentos podendo até acarretar problemas de saúde, como postura, reações alérgicas, má circulação causada por roupas apertadas, de transpiração por tecidos com má condutibilidade de calor, problemas psicológicos pela imposição dos pais ao fazer a criança usar roupas desconfortáveis e inadequadas, entre outros.

\subsection{ASPECTOS INCLUSIVOS PARA O DESIGN DE MODA PARA CRIANÇAS COM CEGUEIRA}

É por meio da aparência que as pessoas transmitem mensagens sobre si mesmas, e as roupas são de extrema importância nessa transmissão, podendo ser conservadoras, ousadas, modernos, formais, casuais ou de qualquer estilo que expresse identidade. "As pessoas se vestem para serem vistas", essa frase de Lipovetski (1989) explica porque os designers são projetados para o sentido da visão como afirmam Munari (1998); Oliveira (1998) e Maximiliano e Tomasulo (2013).

Pessoas com deficiências também precisam expressar sua identidade, ter acesso a moda e aprender sobre vestir-se adequadamente, e sentir-se parte atuante da sociedade. A moda inclusiva é uma proposta de moda que procura incluir tipos de corpos que a indústria hoje não contempla havendo uma preocupação em direcionar para mercados cada vez mais específicos, o que se reflete no desenvolvimento de projetos de criação de produtos para consumidores e portadores de falta de mobilidade, sejam físicas, psíquicas el ou visuais (AULER, 2014).

A proposta de inclusão para o deficiente visual, por meio do vestuário, é diferente do deficiente físico, que necessita de modelagens que se adaptem a suas características específicas. A maior dificuldade para o deficiente visual na hora de se vestir é a combinação das peças, cores e modelos. Para auxiliá-los, foi criada a etiqueta em Braile, que deve identificar o tamanho, cor, tipo de tecido, lavagem e modelo da peça, pretendendo remover grandes barreiras de 


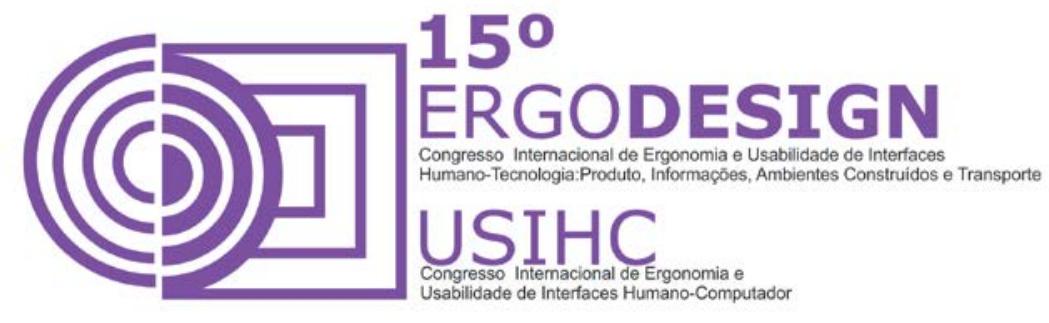

comunicação. Como afirma NEVES et al. (2011), atualmente já existem empresas confeccionando essa etiqueta e possibilitando sua produção em larga escala, mas seu uso ainda não é obrigatório, segundo matéria publicada no JORNAL ESTADO DE SÃO PAULO (2011).

A etiqueta em Braile contribui muito para o deficiente visual adulto, mas no caso das crianças a situação é bem diferente, mesmo que a criança exerça a liberdade de fazer suas próprias escolhas, pois o consumidor infantil está cada vez mais exigente por possuir cada vez mais acesso as informações, ainda são os pais que compram suas roupas (DAL BOSCO, 2014).

Em 2009, foi lançado o Concurso Moda Inclusiva, que conta com a participação de estudantes e profissionais da área de todo o País, onde são apresentadas propostas de moda para pessoas com deficiência. Os melhores trabalhos são apoiados com fornecimento de tecido para a confecção das roupas e participam do desfile final em um grande evento. Inédito no âmbito internacional, o Concurso é anual e incentiva os participantes a lançarem um olhar fashion e desenvolverem soluções que facilitem o cotidiano da pessoa com deficiência. A criação de etiquetas e solados de calçados em braile, por exemplo, fornecem ao consumidor maiores informações sobre o produto e promove a inclusão social do indivíduo. Essa iniciativa propõe uma reflexão comportamental e estimula profissionais e o próprio mercado da moda a abordarem o tema. Hoje é possível encontrar trabalhos acadêmicos que discorrem sobre moda inclusiva, e assim a discussão perpassa a sociedade, e todos os envolvidos disseminam este conceito (AULER, 2014).

Em análise do concurso Moda Inclusiva, Dal Bosco (2014), descreve que, durante as várias edições, muitas alternativas criativas foram propostas para facilitar a vida de pessoas com deficiência visual, desenvolvidas com as seguintes características: aplicações de flores em relevo para estimular o tato; aplicação em Braille com a identificação do produto, peças com técnicas de costura em alto relevo, para estimular o desenvolvimento tátil, peças com abertura frontal (total) em velcro guiada por botões, e uma etiqueta interna descritiva em Braille especificando a cor, o modelo e o tamanho da roupa. Peças práticas como: colete possuindo ilhós interno nos bolsos esquerdo e direito, que acomodam fones de ouvido de aparelhos de música e/ou celular e os mantém sempre presos ao colete, dando maior segurança e liberdade para as mãos; abertura total na blusa em zíper na lateral, para facilitar o ato de vestir e despir.

Brito et al (2011), fala sobre o projeto "Design de Moda como Inclusão Social de Portadores de Deficiência Visual" que foi o $1^{\circ}$ colocado na categoria Responsabilidade Social do evento Inova Senai 2010, onde foram analisadas as dificuldades encontradas pelos deficientes visuais com relação ao vestuário. A intenção do projeto era criar uma coleção de 10 looks infantis femininos, que estimulem a aprendizagem e o desenvolvimento sensorial, por meio do design de moda, métodos de costura diferenciados e aplicações de bordados. A peça escolhida para ser desenvolvida com acompanhamento no processo fabril e estudo de viabilidade econômica foi um vestido com bordados em Braille, dentro do tema geral da coleção "Liberdade". A coleção contém aplicações com resíduos têxteis, texturas formadas por técnicas diferenciadas de costura no próprio tecido, tag com versão em Braille, explicação do método de conservação e do tema da peça, bolso interno com bordados e bolso externo com textura em alto relevo. 


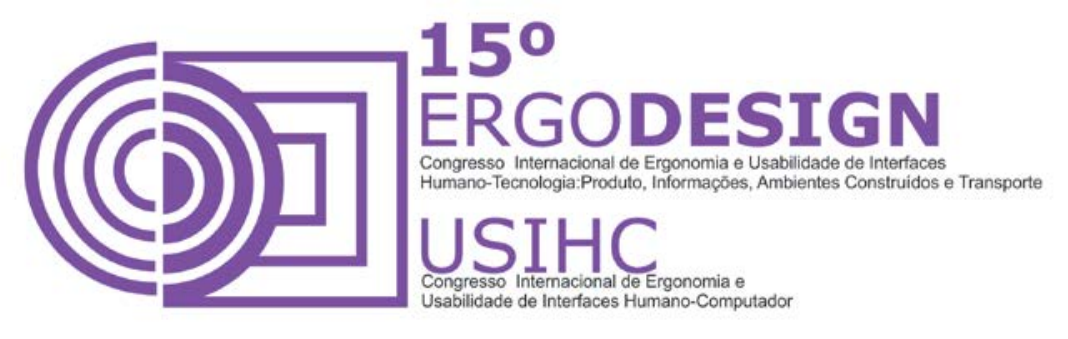

Não há registro se algumas dessas criações foram confeccionadas para o mercado consumidor. As empresas estão sendo pressionadas por estes consumidores a reconhecerem a necessidade de ter um produto inovador que surpreenda o seu público alvo. Segundo Brito et al (2011), não existem criadores e empresas que se preocupam com o público infantil com deficiência visual, mas sim, um grande mercado com peças coloridas, estampas de personagens e lojas aconchegantes adaptadas com brinquedos.

Martins (2005) ao abordar o conforto no vestuário, afirma que este não pode ser usado para todos os usuários porque possuem diferentes características, como: idade, gênero, tipo físico, atitudes. Portanto, quando se projeta determinado produto, é necessário ter uma compreensão de sua demanda. No caso dos produtos do vestuário infantil, este fator é fundamental porque os consumidores são de variadas faixas etárias, e com necessidades características específicas a cada uma delas.

Para a criança em desenvolvimento, a relação entre o real e o imaginário é de grande importância, no qual o vestuário pode contribuir como ferramenta de estímulo à imaginação, à criatividade e a construção da identidade, através de elementos que remetem ao lúdico e a fantasia. Para Maximiliano e Tomasulo (2013), Com exceção da visualização de imagens e cores, a moda passou a ser algo que nos proporciona experiências não apenas visuais, mas também táteis e sensoriais. É essencial manusear os tecidos e testar suas sensações, propriedades e como se comportam quando em contato com o corpo, respeitando caimentos e volumes. O tato é estimulado quando sentimos as diferentes texturas que os tecidos possuem e, combinando tecidos diferentes. Mas será que essas experiências estão sendo vividas pelas crianças, principalmente pelas que tem deficiência visual?

O estímulo tátil é de fundamental importância para o desenvolvimento de crianças cegas, que necessitam adaptar-se às diferentes texturas e ao sistema Braille. Para Brito et al (2011), a experiência tátil por meio do vestuário é um meio de incluir tanto os próprios deficientes, que serão beneficiados com peças que facilitem sua identificação e desenvolvimento do estímulo tátil, quanto os pais cegos e demais consumidores, que passam a conhecer, através da roupa, o sistema Braille e a importância da inclusão social na moda.

\section{CONSIDERAÇÕES FINAIS}

Este discutiu as relações entre moda e design inclusivo para crianças com cegueira, e demonstrou o extenso campo de pesquisa a ser percorrido para que se possa melhor compreender como o mercado está trabalhando o vestuário para as pessoas com baixa visão, principalmente crianças. Novos estudos devem abordar também de forma mais completa a interação da criança com deficiência visual e sua roupa, a fim de se identificar os aspectos mais diretamente relacionados às necessidades e expectativas do usuário. Neste sentido, o design deve buscar na interdisciplinaridade algumas respostas para as diversas questões levantadas neste estudo. O mercado deve instigar a pesquisa continuada sobre moda inclusiva e o respeito do corpo a ser vestido para produzir produtos e serviços que atendam ás necessidades do 


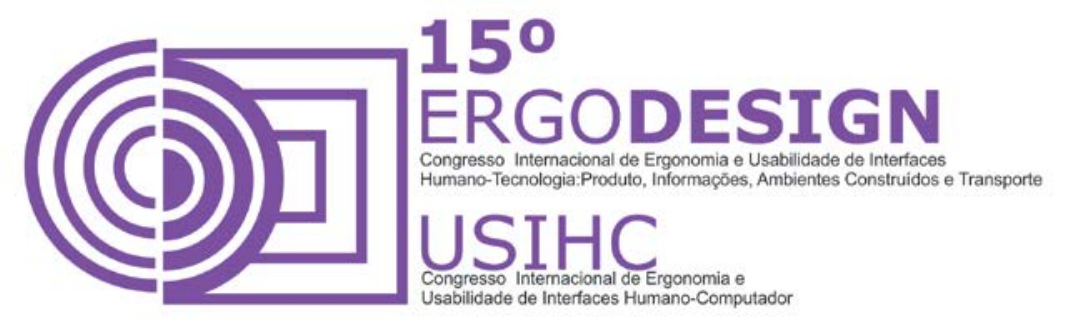

público e possibilitem o prazer de sentir-se bem com o vestuário, e que proporcionem tanto conforto físico quanto bem estar emocional.

AGRADECIMENTOS: Agradeço a CAPEs, pela bolsa de auxílio.

\section{REFERÊNCIAS}

AULER, Daniela. Moda Inclusiva: Perguntas e respostas para atender o tema. Disponível em: http://www.pessoacomdeficiencia.sp.gov.br/usr/share/documents/MODA INCLUSIVA DIGITAL CARTILHA FINAL.pdf acessado em 12/12/2014

ANCHIETA, Adrienne Rabelo. A complexidade da moda como profissão. Disponível em http://www.coloquiomoda.com.br/anais/anais/2-Coloquio-de-Moda 2006/artigos/6.pdf Acesso em: 20/12/2014.

AMIRALIAN, Maria Lúcia T. M. Compreendendo o Cego: Uma visão psicanalistica da cegueira por meio de Desenho - Estórias. São Paulo: Casa do Psicólogo, 1997.

ARNHEIM, Rudolf. Arte e Percepção Visual: uma psicologia da visão criadora. São Paulo: 1996. Trad. Terezinha de Faria.

BARBOSA, Rita Claudia Aguiar. QUEDES, Walkiria. Vestuário e infância: entre a adequação e as determinações sociais. Disponível em http://fido.palermo.edu/servicios dyc/encuentro2007/02 auspicios publicaciones/actas diseno/articulos pdf/A100.pdf Acesso em 28/12/2014

BRITO, Inayê Jorge Gomes de, et al. O Design de Moda como inclusão social de portadores de deficiência visual. Revista Eletrônica de Educação e Tecnologia do SENAI-SP. ISSN 1981-8270. v.4, n.9, out.2010. Disponível em: http://revistaeletronica.sp.senai.br/index.php/seer/article/viewFile/154/98 acessado em 10/11/2014.

CARDOSO, Tânia Patrícia. A influência da publicidade no consumo da moda infantil. UEM; Maringá 2011. Disponível em: http://www.dfe.uem.br/TCC/Trabalhos\%202011/Turma\%2031/Tania Cardoso.pdf acessado em:10/11/14.

CUNHA, Ana Cristina Barros da; ENUMO, Sônia Regina Fiorim; CANAL, Cláudia Patrocínio Pedroza. Avaliação cognitiva psicométrica e assistida de crianças com baixa visão moderada. Paidéia (Ribeirão Preto) Vol: 21 Edição: 48 Páginas: 29-39 Publicado: 2011-04 Disponível em http://www.scielo.br/scielo.php?script=sci arttext\&pid=S0103-863X2011000100005 acessado 11/11/14.

DAL BOSCO, Glória Lopes da Silva. Moda Inclusiva: uma análise estética funcional. Disponível em: http://coloquiomoda.com.br/anais/anais/10-Coloquio-de-Moda 2014/COMUNICACAO-ORAL/CO-EIXO3CULTURA/CO-Eixo-3-Moda-Inclusiva-Uma-Analise-Estetica-e-Funcional.pdf acessado em 06/01/2015

FERREIRA, Francirosy Campos Barbosa. MORELLATO, Alice. Ser, Sentir-se e viver com a cegueira e a estigmatização. Disponível em: file:///C:/Users/Julyka/Downloads/pontourbe-1092-11-ser-sentir-se-eviver-com-a-cegueira-e-a-estigmatizacao.pdf Acessado em 28/12/2014

Estadão. Jornal do Estado de São Paulo online. Disponível em: http://saopaulo.estadao.com.br/noticias/geral,etiqueta-em-braile-deixa-moda-mais-acessivel-imp-,668553

Acessado em 04/01/2015. 


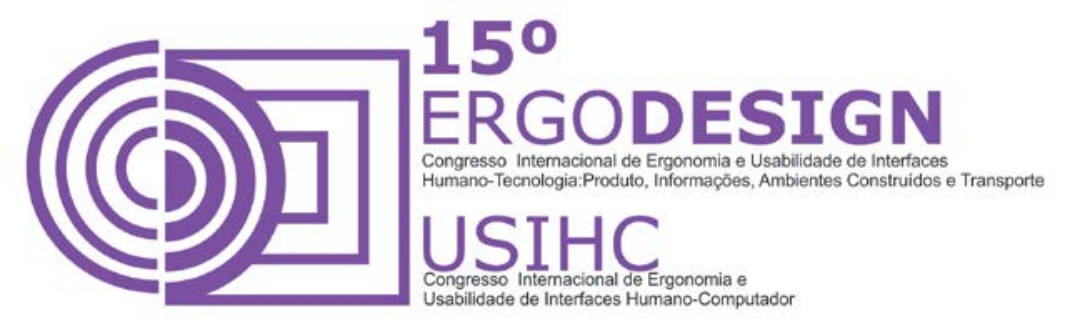

FERRONI, Marília Costa Câmara; GASPARETTO, Maria Elisabete Rodrigues Freire. Escolares com baixa visão: percepção sobre as dificuldades visuais, opinião sobre as relações com comunidade escolar e o uso de recursos de tecnologia assistiva nas atividades cotidianas. Rev. bras. educ. espec., Marília, $\quad$ v.18, n. 2, jun. 2012.2 Disponível em http://www.scielo.br/scielo.php?script=sci arttext\&pid=S1413-65382012000200009\&lng=pt\&nrm=iso Acesso em 14 dez.2014.

GERBER, Paul J.; GRIFFIN, Harold C.Desenvolvimento Tátil e suas Implicações na Educação de Crianças Cegas. Disponível em: http://www.ibc.gov.br/?itemid=101 Acessado em: 13/12/2014

GONÇALVES, Eliana; BEIRAO, José Alfredo. Aspectos Ergonômicos: evolução do vestuário infantil. 2007. Disponível em http://fido.palermo.edu/servicios dyc/encuentro2007/02 auspicios pub... Acessado em: 20/12/2014

GUIMARÃES, M. A dimensão ambiental na educação. Campinas: Papirus, 1995.

IBGE. Censo Demográfico 2010. Disponível em: http://biblioteca.ibge.gov.br/visualizacao/periodicos/94/cd 2010 religiao deficiencia.pdf Acessado em: 20/12/2014.

LIMA, Ana C.E. FERREIRA, Jeniffer Cristiane. SILVA, Rômulo Gonçalves da. Deficiência Visual: vida independente e inclusão. Disponivel em http://www.faeteri-caxias.net/revista/index.php/edutec/article/view/42

Acessado 20/12/2014

LIMA JÚNIOR, Geraldo Coelho. Design de Moda e Percepção Tátil. Disponível em: http://www.coloquiomoda.com.br/anais/anais/2-Coloquio-de-Moda 2006/artigos/49.pdf Acessado em $\underline{28 / 12 / 2014}$

LIPOVETSKY, Gilles: O Império do Efêmero: a moda e seu destino nas sociedades modernas. São Paulo: Companhia da Letras, 1989. 9a reimpressão 2006.

MAXIMILIANO, Cristiani. TOMASULO, Simone Batista. $O$ ensino de moda e a inclusão de deficientes visuais. E-Tech: Tecnologias para Competitividade Industrial, Florianópolis, v. 7, n. 2, p.135-164, 2013.

MONTAGU, Asheley. Tocar - O significado humano da pele. São Paulo: Summus Editorial, 1986. Trad. Maria Silvia Mourão Netto.

MUSEEN, Paul Henry; CONGER, Joan Janeway; KAGAN, Jerome. Desenvolvimento e personalidade da criança. 4. ed. São Paulo: Harbra, 1988. 553 p.

MUNARI, Bruno. Das coisas nascem coisas. São Paulo: Martins Fontes, 1998.

NEVES, Manuela. BARRETO, Marise. NEVES, Jorge. Design de uma Etiqueta para pessoas com Deficiência Visual. VI CIPED,2011. Disponível em: https://repositorium.sdum.uminho.pt/bitstream/1822/15745/1/Artigo\%20Etiqueta.pdf acessado em 20/12/2014

OLIVEIRA, J. V. G. Arte e visualidade: A questão da cegueira. Revista Benjamin Constant,1998, 4(10), 7-10. 


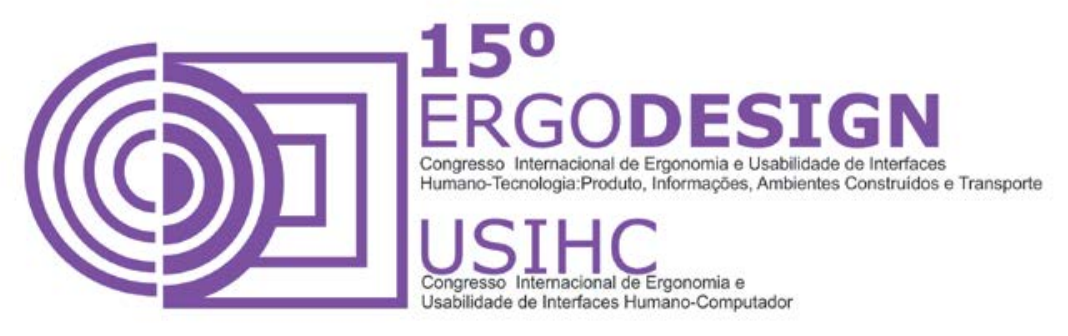

OLIVEIRA, M. B. \& OLIVEIRA, M. K. (Orgs.). (1999). Investigações cognitivas: Conceitos, linguagem e cultura. Porto Alegre: Artmed.

OLIVEIRA, Fátima I.W.de. BIZ, Vanessa Aparecida. FREIRE, Maísa. Processo de inclusão de alunos deficientes visuais na rede regular de ensino: confecção e utilização de recursos didáticos adaptados. Disponível em: https://scholar.google.com.br/scholar?bav=on.2,or.r cp.r qf.\&bvm=bv.82001339,d.eXY\&biw=1366\&bih=6 67\&dpr=1\&um=1\&ie=UTF-8\&lr\&q=related:tAXhb5pGuMB27M:scholar.google.com/ acessado em 20/12/2014

PINHEIRO, Isabela Ferreira da Silva. SANCHES, Maria Celeste de Fátima. O produto de moda como fator de estimulo a fantasia e imaginação infantil. Disponível em http://www.coloquiomoda.com.br/anais/anais/2-Coloquio-de-Moda 2006/artigos/54.pdf acessado em 20/12/2014

RESENDE, Cláudia Arantes Pires Di Guimarães. MACHADO, Janine Brito. SOUTO, Keila Cristina Dias. VIEIRA, Sandra da Silva. MARTINS, Eliecília F. Estudo sobre as vestimentas para deficientes visuais. Disponível em; http://www.coloquiomoda.com.br/anais/anais/7-Coloquio-de Moda 2011/GT13/Poster/P 89620 A relacao do Deficiente Visual com as vestimentas.pdf acessado em 20/12/2014

ROCHA, R. de C. História Da Infância: reflexões acerca de algumas concepções correntes. Revista ANALECTA, Guarapuava: Unicentro, v. 3, n. 2, p. $51-63$ jul/dez. 2002.

SARMENTO, Manuel Jacinto. Imaginário e culturas de infância. Minho, 2003. Disponível em: http://old.iec.uminho.pt/promato/textos/imacultinfancia.pdf Acessado em: 12 dezembro 2014.

SASSAKI, Romeu Kazumi. Inclusão/Construindo uma sociedade para todos. $2^{\mathrm{a}}$ ed., Rio de Janeiro: WVA, 1997.

SOUZA, Carolina Molina Lucenti de. BATISTA, Cecilia Guarnieri. Psicologia - reflexão e crítica. Vol: 21 Edição: 3 Páginas: 383-391 Publicado: 2008

ULBRICHT, Vania Ribas. Et al. Os Deficientes visuais e a aprendizagem da representação espacial. Gráfica 2011.

ZANATTA, Tatiana Anselmo Ferreira. Modelagem Infantil: Dificuldades Antropométricas atuais. UNESC.

Disponível

em:

http://repositorio.unesc.net/bitstream/handle/1/2507/Tatiana\%20Anselmo\%20Ferreira\%20Zanatta.pdf?se quence=1 acessado em 11/11/2014. 